\title{
Thermodynamic Study of Interactions between ZnO and ZnO Binding Peptides Using Isothermal Titration Calorimetry
}

\author{
Marion J. Limo and Carole C. Perry* \\ Biomolecular and Materials Interface Research Group, Interdisciplinary Biomedical Research Centre, School of Sci- \\ ence and Technology, Nottingham Trent University, Clifton Lane, Nottingham, NG11 8NS, U.K.
}

\begin{abstract}
Whilst material specific peptide binding sequences have been identified using a combination of combinatorial methods and computational modelling tools, a deep molecular level understanding of the fundamental principles through which these interactions occur and in some instances modify the morphology of inorganic materials is far from being fully realized. Understanding the thermodynamic changes that occur during peptide-inorganic interactions and correlating these to structural modifications of the inorganic materials could be the key to achieving and mastering control over material formation processes. This study is a detailed investigation applying isothermal titration calorimetry (ITC) to directly probe thermodynamic changes that occur during interaction of $\mathrm{ZnO}$ binding peptides (ZnO-BPs) and $\mathrm{ZnO}$. The ZnO-BPs used are reported sequences G-12 (GLHVMHKVAPPR), GT-16 (GLHVMHKVAPPR-GGGC) and alanine mutants of G-12 (G-12A6, G-12A11 and G-12A12) whose interaction with ZnO during solution synthesis studies have been extensively investigated. The interactions of the $\mathrm{ZnO}-\mathrm{BPs}$ with $\mathrm{ZnO}$ yielded biphasic isotherms comprising both an endothermic and an exothermic event. Qualitative differences were observed in the isothermal profiles of the different peptides and $\mathrm{ZnO}$ particles studied. Measured $\Delta G$ values were between -6 and $-8.5 \mathrm{kcal} / \mathrm{mol}$ and high adsorption affinity values indicated the occurrence of favourable $\mathrm{ZnO}-\mathrm{BP}-\mathrm{ZnO}$ interactions. ITC has great potential in its use to understand peptide-inorganic interactions and with continued development, the knowledge gained may be instrumental for simplification of selection processes of organic molecules for the advancement of material synthesis and design.
\end{abstract}

\section{INTRODUCTION}

Following biomimetic strategies, there is an increasing body of evidence demonstrating that combinatorially selected material binding peptides such as those identified using phage display (PD) and post selection tailored peptides are able to control the morphology of non-biological inorganic materials. ${ }^{1-11}$ Peptides have also been shown to act as stabilizers, reducing agents, catalysts or inhibitors when incorporated in solution syntheses of inorganic materials. ${ }^{10,12,13}$ Great prospects lie in the use of material binding peptides to improve artificial material formation processes following more environmentally sustainable bioinspired methods. The specificity between inorganic crystal surfaces and material binding peptides and the exact mechanisms of their interaction are however not clearly understood.,3,14 In biomineralization processes, where minerals are produced by living organisms, it is thought that biomolecules may control mineral formation by modification of the energy barriers at the interface.3,15 Similarly, there may be a direct link between thermodynamic changes that occur at the peptide-inorganic interface and peptide-directed structural modification of inorganic materials. Therefore, understanding the energetic changes that occur during peptide-inorganic interactions and correlating these to structural modifications of the inorganic materials could be the key to advancing material synthesis/design and may also reveal key principles through which material structure is controlled in nature..$^{15-17}$

Of specific interest, in-house studies have been carried out to understand the fundamental principles through which $\mathrm{ZnO}$ binding peptides ( $\mathrm{ZnO}-\mathrm{BPs}$ ) interact with and modify $\mathrm{ZnO}$ growth process and morphology. ${ }^{6,8,18}$ In a recent contribution, the mechanisms through which specific $\mathrm{ZnO}$ binding peptides ( $\mathrm{ZnO}-\mathrm{BPs}$ ) interact with and modify the growth process and morphology of $\mathrm{ZnO}$ during solution synthesis was described. ${ }^{8}$ The peptides used in the study were PD identified G-12 (GLHVMHKVAPPR) peptide, its derivative GT-16 (GLHVMHKVAPPR-GGGC) and alanine mutants of the G-12 peptide. ${ }^{1,8}$ The mutants were selected on the basis of peptide stability calculated in silico i.e., molecular dynamics (MD) simulations were used to monitor the conformation and stability of mutants generated by single point substitution of alanine into each position in G-12 sequence. ${ }^{8}$ The mutants selected were G-12A6 (GLHVMAKKAPPR) and G-12A11 (GLHVMHKVAPAR), determined to be more stable than G-12 peptide and G-12A12 (GLHVMHKVAPPA) found to be the most unstable sequence generated in solvated and non-solvated states. ${ }^{8}$ When incorporated in $\mathrm{ZnO}$ synthesis using a reported $\mathrm{Zn}\left(\mathrm{NO}_{3}\right)_{2} \cdot 6 \mathrm{H}_{2} \mathrm{O}$-HMTA method, ${ }^{1} \mathrm{G}-12$, G-12A11 and G-12A12 all adsorbed to $\mathrm{ZnO}$ rods decreasing the aspect ratio of the crystals in comparison to rods formed in the absence of peptide. ${ }^{8}$ Uniquely, incorpora- 
tion of G-12A6 peptide resulted in the formation of microsphere structures. ${ }^{8}$ Using a different synthesis method, the $\mathrm{ZnAc}_{2}-\mathrm{NH}_{3}$ system, ${ }^{19}$ in comparison to G-12A6, G-12 had a greater ability to inhibit $\mathrm{ZnO}$ formation by stabilizing the intermediate product layered basic zinc acetate (LBZA). ${ }^{8}$

Herein, to extend our understanding, isothermal titration calorimetry (ITC) has been employed to directly probe thermodynamic changes during interaction of the aforementioned $\mathrm{ZnO}-\mathrm{BPs}$ with $\mathrm{ZnO}$. Few studies have kinetically and thermodynamically characterized the interaction of $\mathrm{ZnO}-\mathrm{PBs}$ with $\mathrm{ZnO}$ surfaces. Adsorption studies of fluorescent labelled EM-12 (EAHVMHKVAPRP) peptide (as well as alanine mutants, random rotations and short segments/truncations of the EM-12 sequence) to $\mathrm{ZnO}$ have been reported. ${ }^{20,21}$ Thermodynamic parameters of interaction were estimated from Langmuir adsorption isotherms and van't Hoff equations. ${ }^{20,21}$ In the study reported by Yokoo and colleagues, ${ }^{20}$ change in Gibbs free energy $(\Delta G)$ values of tagged $\mathrm{ZnO}$-BPs were estimated to lie in-between -7.17 and $-8.37 \mathrm{kcal} / \mathrm{mol}^{20}$ Interactions were seen to be enthalpy driven with the main contribution from $\Delta H$ values. ${ }^{20}$ The adsorption process was mainly attributed to hydrogen bonding and electrostatic interactions through charged residues of the peptides. ${ }^{20}$ Nuclear magnetic resonance ( ${ }^{1} \mathrm{H}$ NMR) has also been used to determine the binding affinity of two phage display identified ZnO-BPs (HSSHHQPKGTNP and HHGHSPTSPQVR) for $\mathrm{ZnO}$ particles by determining the line broadening effects during interaction of the peptides with different concentrations of $\mathrm{ZnO}$ and assuming a 1.1 Langmuir binding model. ${ }^{22}$ HHGHSPTSPQVR peptide was found to be the stronger binder for the $\mathrm{ZnO}$ substrate used..$^{22}$

The applications of ITC continue to evolve from conventional biomolecular recognition reactions into diverse areas of interest in the medical/academic fields and industrial sector. An example is the developing use of ITC to study interactions between proteins/peptides and inorganic nanoparticles for biomedical applications..$^{16,23-25}$ Though the use of ITC to study biotic-abiotic interactions is in its infancy it has great potential as it does not require labelling or immobilization of the interacting components and more exceptionally, it can directly measure molar enthalpy of interaction and determine all thermodynamic parameters (enthalpy change $(\Delta H)$, entropy change $(\Delta S)$, $K_{A}$ and $\Delta G$ ) in a single experiment. ${ }^{26,27}$ Using ITC, the interaction of the studied $\mathrm{ZnO}$-BPs with $\mathrm{ZnO}$ is seen to be an energetically favourable process and is described to involve different events some of which may be occurring simultaneously i.e. peptide-solvent, substrate-solvent, peptide-surface, possible conformation changes between bound and free peptide states and peptide-peptide interactions.

\section{EXPERIMENTAL SECTION}

Materials. Zinc nitrate hexahydrate $\left(\mathrm{Zn}\left(\mathrm{NO}_{3}\right)_{2} \cdot 6 \mathrm{H}_{2} \mathrm{O}\right)$ and 1,3-hexamethylenetetramine (HMTA, $\mathrm{C}_{6} \mathrm{H}_{12} \mathrm{~N}_{4}$ ) were purchased from Sigma Aldrich for $\mathrm{ZnO}$ synthesis. Materials for the synthesis of peptides were; Fmoc-protected amino acids and 2-(1H-benzotriazole-1-yl)-1,1,3,3tetramethyluronium hexafluorophosphate (HBTU) purchased from CEM Corporation, amino acid-preloaded
Wang resins from Novabiochem , Piperazine, diisopropyl ethylamine (DIEA), thioanisole (TIS, $\mathrm{C}_{7} \mathrm{H} 8 \mathrm{~S}$ ), trifluoroacetic acid (TFA, $\mathrm{C}_{2} \mathrm{HF}_{3} \mathrm{O}_{2}$ ) and 3,6-dioxa-1,8octanedithiol (DODT, $\mathrm{C}_{6} \mathrm{H}_{14} \mathrm{O}_{2} \mathrm{~S}_{2}$ ) from Sigma Aldrich. All materials were used without any further treatment. Where required, distilled-deionized water $\left(\mathrm{ddH}_{2} \mathrm{O}\right)$ having conductivity measurement of less than $1 \mu \mathrm{S} \mathrm{cm}^{-1}$ at 25 ${ }^{\circ} \mathrm{C}$ was used.

Synthesis of Peptides and ZnO. The synthesis and characterization of peptides and $\mathrm{ZnO}$ particles used in this study has previously been described in detail. ${ }^{8}$ Peptides were synthesized via Fmoc chemistry using microwave assisted solid phase peptide synthesis technique (Libertyı instrument CEM Corporation). ${ }^{8}$ Peptide purity and molecular weight were ascertained using reverse phase high performance liquid chromatography (Dionex RP-HPLC) and matrix-assisted laser desorption/ionization time-of-flight mass spectrometry (Bruker Ultraflex III MALDI-TOF). ${ }^{8} \mathrm{ZnO}$ particles were synthesized following a method using $\mathrm{Zn}\left(\mathrm{NO}_{3}\right)_{2} \cdot 6 \mathrm{H}_{2} \mathrm{O}$ and HMTA to form elongated twinned rods and a modification of the method incorporating GT-16 peptide to form lower aspect ratio $\mathrm{ZnO}$ twinned platelets. ${ }^{1,6,8}$ Synthesized $\mathrm{ZnO}$ particles had been characterized using several techniques; scanning electron microscopy (JEOL JSM-840A SEM), Energy dispersive X-ray (EDX) analysis, X-ray diffraction (X'Pert PRO XRD), Fourier transform infrared spectroscopy (Nicolet Magna IR-75o), and Thermogramietric analysis (Mettler Toledo TGA/SDTA 851e). ${ }^{8}$ Herein, additional characterization of the $\mathrm{ZnO}$ particles was carried out before ITC experiments. Raman spectroscopy (Nicolet iS 5o) was used to identify the functional groups present in the $\mathrm{ZnO}$ particles, specifically to characterize peptide adsorption to $\mathrm{ZnO}$ platelets. The surface chemical constituents of the $\mathrm{ZnO}$ platelets were identified using $\mathrm{X}$ ray photoelectron spectroscopy (VG Scientific ESCALAB Mkii XPS) as previously described. ${ }^{28}$ The surface area of $\mathrm{ZnO}$ was determined using a Quantachrome Monosorb nitrogen gas adsorption instrument and the single-point Brunauer-Emmett-Teller (BET) method. The surface area of the $\mathrm{ZnO}$ rods was determined to be $3.8 \mathrm{~m}^{2} / \mathrm{g}$ and the surface area of $\mathrm{ZnO}$ platelets synthesized using GT-16 was $4.2 \mathrm{~m}^{2} / \mathrm{g}$. A dissolution study was conducted to confirm the reproducibility of $\mathrm{ZnO}$ sample preparation by Inductively coupled plasma atomic emission spectroscopy (ICPOES, Perkin Elmer Optima 210oDV) quantification of the amount of $\mathrm{Zn}^{2+}$ ions dissolved from $\mathrm{ZnO}$ suspensions prepared for ITC experiments. The concentration of $\mathrm{Zn}^{2+}$ ions was determined to be $0.10 \pm 0.01 \mathrm{mM}$. There was no significant difference (ANOVA, $\mathrm{p}$ value $>0.05, \mathrm{n}=21$ ) in the amount of $\mathrm{Zn}^{2+}$ ions present between samples prepared.

ITC Studies of Interactions between $\mathrm{ZnO}$-BPs and ZnO. Thermodynamic binding experiments were carried out using a MicroCal VP-ITC Northampton, MA instrument by GE Healthcare. Interacting components were prepared in filtered $\mathrm{dd}_{2} \mathrm{O}$. In each experiment, the prepared peptide solution and the solution with suspended $\mathrm{ZnO}$ were degassed for 7 min using a Thermovac before loading in the ITC. Preliminary experiments were carried out to optimize the experimental conditions. The parameters chosen for the experiments were; temperature of 25 
${ }^{\circ} \mathrm{C}$, a reference power of $15 \mu \mathrm{cal} / \mathrm{sec}$, syringe stirring speed of $394 \mathrm{rpm}$, a peptide concentration of $3.1 \mathrm{mM}$ in a total volume of $280 \mu \mathrm{l}$ injected periodically in $10 \mu \mathrm{l}$ aliquots into the sample cell containing $1.4 \mathrm{ml} \mathrm{ZnO}$ suspension (o.1

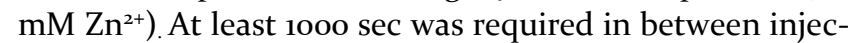
tions to allow the baseline to return to equilibrium after each injection. A spacing of $1200 \mathrm{sec}$ was required for the first 10 injections and a spacing of 1000 sec for the remaining 18 injections. In some experiments with GT-16, the spacing of the first 10 injections needed to be increased to 1600 sec. The heat effects measured in the peptide into water dilution experiments performed under identical timing of aliquot additions were subtracted from the heat effects of interaction (titration of peptide into $\mathrm{ZnO}$ suspension). Other dilution experiments performed were dilution of water into the cell containing the $\mathrm{ZnO}$ particles and the dilution of water into water which produced negligible heat measurements. Each experiment was at least duplicated. Data analysis was conducted using ORIGIN 7.0 software and fit using a non-linear leastsquares algorithm with one set of sites and two sets of independent sites model from MicroCal. ${ }^{29}$

\section{RESULTS AND DISCUSSION}

ITC experiments were carried out to measure heat effects taking place during the interaction of peptide with $\mathrm{ZnO}$ particles. The interactions were studied in aqueous media as in the synthesis studies. ${ }^{1,6,8}$ Further information in support of the choice of media for ITC experiments is given in $\mathrm{S}_{1}$ of supporting information (SI). ITC experiments were designed to; (i) monitor heat effects of interaction between $\mathrm{ZnO}$ and the $\mathrm{ZnO}$-BPs and identify the driving forces of interaction, (ii) determine if alanine mutants of G-12 had different thermodynamic signatures in their adsorption process compared to the original sequence, (iii) determine if differences in adsorption characteristics could be detected for different peptides with a single crystal morphology and an individual peptide with different crystal morphologies and (iv) possibly identify a direct link between thermodynamic changes that occur at the peptide-inorganic interface and the observed peptide directed structural modifications of $\mathrm{ZnO}$.

ITC Study of Interactions of G-12 and its Alanine Mutants with ZnO Rods. $\mathrm{ZnO}$ solution synthesis studies with peptide had demonstrated that a single point mutation in G-12 sequence to form G-12A6 resulted in a drastic change in $\mathrm{ZnO}$ morphology, unlike with G-12A11 and G${ }_{12} \mathrm{~A} 12$ (Figure 1). ${ }^{8}$ Synthesis studies also showed that $\mathrm{ZnO}$ BPs could strongly/irreversibly adsorb to $\mathrm{ZnO} .^{8}$ Here, ITC was used to directly monitor the interaction of $\mathrm{ZnO}$ rods (48-hr precipitates obtained from synthesis using $\mathrm{Zn}\left(\mathrm{NO}_{3}\right)_{2} \cdot 6 \mathrm{H}_{2} \mathrm{O}$ and HMTA) with $\mathrm{G}-12$ and its alanine mutants (G-12A6, G-12A11 and G-12A12). The interactions produced measurable heat effects (Figure 1). With each peptide, two binding events occurred, an endothermic event followed by an exothermic event evidenced by positive and negative changes in differential power $(D p)$ respectively. Peptide sequence dependent qualitative differences in the shapes of the isothermal profiles were observed.
Determination of surface coverage is important for quantification of binding potency and is also an indicator of whether monolayers or multilayers were formed. $25,30 \mathrm{In}$
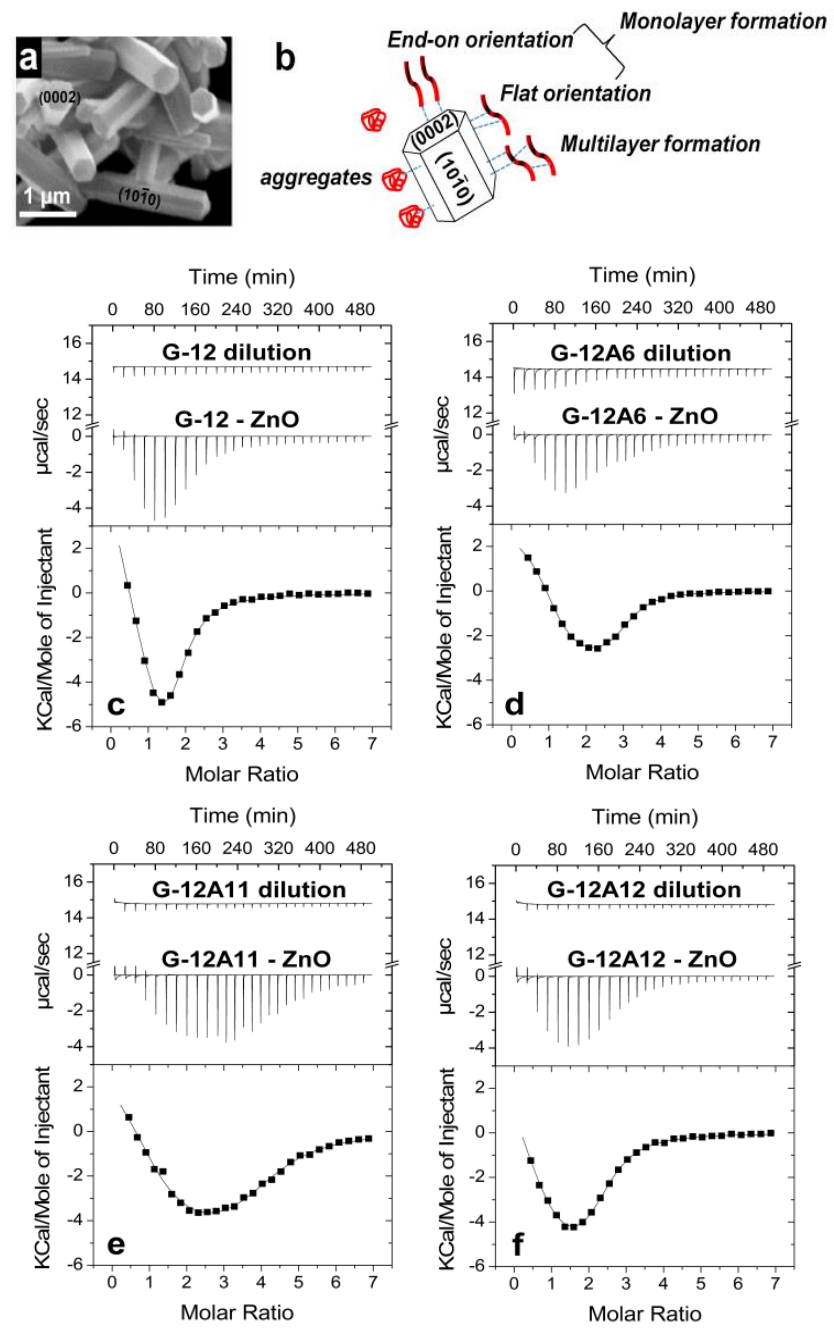

Figure 1. (a) SEM micrographs $\mathrm{ZnO}$ twinned rods, $\mathrm{L} / \mathrm{D}=8.92$ \pm 3.26 collected after 48 hrs of synthesis using the $\mathrm{Zn}\left(\mathrm{NO}_{3}\right)_{2} .6 \mathrm{H}_{2} \mathrm{O}$ and HMTA system, (b) schematic representation of possible modes of interaction of peptide with $\mathrm{ZnO}$ surface (c-f) ITC isotherms showing heat effects measured in titration of G-12 and its alanine mutants G-12A6, G-12A11 and G-12A12 (3.1 mM) into suspensions of $\mathrm{ZnO}$ rods (o.1 mM bulk concentration). Dilution heat effect of titrating each peptide into water is also shown.

all the measured interactions, at least $100 \mu \mathrm{l}$ (at least 10 injections) of $3.1 \mathrm{mM}$ peptide was needed to reach saturation. From estimation of the size of peptide molecules using molecular dynamics (MD) software, the theoretical maximum number of peptide molecules needed to form monolayer coverage (assuming that the peptides adsorbed to the $\mathrm{ZnO}$ surfaces end-on/upright for maximum possible monolayer coverage) on the total surface area of $\mathrm{ZnO}$ rods present in an ITC experiment (based on BET analysis), was less than the amount of peptide experimentally needed to attain saturation in ITC experiments. For example, the number of unit molecules of G-12 estimated to fill a monolayer was $8.91 \times 10^{13}$ and the amount needed to reach saturation in ITC experiments was $2.46 \times 10^{17}$. In all the interactions, the amount of peptide needed to obtain saturation was in great excess of the amount required 
to form monolayer coverage suggesting that dense peptide multilayers were formed on $\mathrm{ZnO}$. It is for this reason that normalized heat effects in $\mathrm{kcal} /$ mole of injectant were plotted against the molar ratio

Table 1. Thermodynamic parameters obtained from ITC measurements of interaction of G-12 and its alanine mutants G-12A6, G-12A11 and G-12A12 (3.1 mM) with $\mathrm{ZnO}$ rods (o.1 mM bulk concentration). Temperature of $298 \mathrm{~K}$ was maintained throughout each experiment. $\Delta S$ and $\Delta G$ were calculated from $\Delta H-T \Delta S=-R T \ln K_{A}=\Delta G$.

$\begin{array}{llllll}\text { Peptide and ZnO } & \text { Dp } & K_{A}\left(\mathrm{M}^{-1}\right) & \Delta H\left(\mathrm{Kcal} \mathrm{mol}^{-1}\right) & T \Delta S\left(\mathrm{Kcal} \mathrm{mol}^{-1}\right) & \Delta G\left(\mathrm{Kcal} \mathrm{mol}^{-1}\right) \\ \text { G-12 - ZnO } & \text { +ve } & 1.40 \times 10^{6} \pm 0.33 \times 10^{6} & 2.36 \pm 0.68 & 10.73 \pm 0.55 & -8.37 \pm 0.13 \\ & \text {-ve } & 9.01 \times 10^{4} \pm 0.32 \times 10^{4} & -7.55 \pm 1.09 & -0.79 \pm 1.06 & -6.76 \pm 0.02 \\ \text { G-12A6- ZnO } & \text { +ve } & 2.65 \times 10^{5} \pm 0.52 \times 10^{5} & 5.47 \pm 3.12 & 12.86 \pm 3.22 & -7.39 \pm 0.10 \\ & \text {-ve } & 6.79 \times 10^{4} \pm 0.62 \times 10^{4} & -15.69 \pm 8.41 & -9.09 \pm 5.79 & -6.60 \pm 0.02 \\ \text { G-12A11 - ZnO } & \text { +ve } & 3.86 \times 10^{5} \pm 2.14 \times 10^{5} & 4.19 \pm 2.07^{*} & 11.80 * & -7.61^{*} \\ & \text {-ve } & 4.51 \times 10^{4} \pm 0.47 \times 10^{4} & -6.69 \pm 1.22 & -0.34 \pm 1.28 & -6.34 \pm 0.06 \\ \text { G-12A12 - ZnO } & \text { +ve } & 4.47 \times 10^{5} \pm 0.76 \times 10^{5} & 5.74 \pm 0.76 & 13.42 \pm 0.86 & -7.69 \pm 0.10 \\ & \text {-ve } & 8.58 \times 10^{4} \pm 0.18 \times 10^{4} & -6.91 \pm 0.78 & -0.55 \pm 0.25 & -6.36 \pm 0.53\end{array}$

(+ve) endothermic, (-ve) exothermic, ${ }^{*}$ ) designates parameters determined from one experiment, other parameters are an average of two measurements.

of the peptide concentration and the bulk concentration of $\mathrm{ZnO}$ determined from the dissolution study (performed using ICP- OES) even though the peptide would only interact with the surface of particles. It has been reported that the effective concentration of surface sites available for interaction $\left(M_{t}{ }^{\prime}\right)$ on particles can be estimated from adsorption studies (Langmuir adsorption isotherms) and BET determined surface area of the particles. ${ }^{11,32}$ However, this may not be applicable in instances such as in this study where multilayer formation occurs with heat effects produced not only during monolayer adsorption. For the adsorption of G-12 and the selected alanine mutants to $\mathrm{ZnO}$, the value $M_{t}^{\prime}$ would represent both the surface sites available on $\mathrm{ZnO}$ as well as the peptide binding sites that allow intermolecular interaction.

To determine the thermodynamic parameters of interaction, the heat effects of diluting peptide into water were first subtracted from the global observed heat effects $\left(\Delta H_{\mathrm{obs}}\right)$ obtained during titration of the peptide into $\mathrm{ZnO}$ particles. Isotherms were then fitted using the two sets of independent binding sites model provided by MicroCal on the basis of the shape of the isotherm having two separate saturation events (Table 1). According to literature, the accuracy of determining the concentration of the syringe component in ITC experiments directly affects the accuracy of determining the parameters $K_{A}$, molar binding ratio $(n)$ and $\Delta H$ whereas the accuracy of determining the concentration of the sample cell component only affects $n .{ }^{33}$ As peptide concentration was known, $K_{A}$ and $\Delta H$ could be estimated but $n$ was not defined because of the uncertainty of determining the concentration of surface binding sites on $\mathrm{ZnO}$.

The interactions of the peptides with the different $\mathrm{ZnO}$ morphologies were favourable; based on the high $\left(>10^{4}\right.$ $\left.\mathrm{M}^{-1}\right)^{21,34,35}$ affinity values obtained and negative values of $\Delta G$ which were estimated to lie in between -6 and -8.5 $\mathrm{kcal} / \mathrm{mol}$. These values were similar to those reported for the adsorption of fluorescent tagged EM-12 (and truncations of the sequence) to $\mathrm{ZnO}{ }^{20}$ ITC is however a faster method that can directly probe thermodynamic parameters of interaction without the requirement for labelling or carrying out experiments at different concentrations or temperatures to estimate thermodynamic parameters. In this study, the values of $\Delta H$ and $\Delta S$ were positive in all endothermic processes of the biphasic isotherms. The surfaces of many metal oxides like $\mathrm{ZnO}$ become hydroxylated in aqueous solution. The polar hydroxylated $\mathrm{ZnO}$ surface attracts and adsorbs water molecules which can either be chemisorbed or physisorbed. ${ }^{6}$ As peptides moved towards the $\mathrm{ZnO}$ surface, peptide conformational changes as well as incorporation or displacement of water molecules may have occurred producing an endothermic heat effects with the largest contribution from positive values of $\Delta S$. Negative $\Delta H$ values for the exothermic process indicated the occurrence of non-covalent interactions like hydrogen bonding, van der Waals forces or electrostatic interactions. ${ }^{26,27,37}$ Although determination of changes in non-covalent interactions $\left(K_{A}, \Delta H, \Delta S\right)$ may not rigorously define interactions at an atomic scale, the information obtained may be a guideline towards understanding binding/adsorption processes. ${ }^{27}$ As the amount of adsorbed peptide was greater than that needed to form monolayer coverage, the observed exothermic heat effect was attributed to contributions from both peptide-surface adsorption as well as peptide-peptide interactions. Two saturation events could have taken place; peptide saturation of the $\mathrm{ZnO}$ surface and peptide binding to peptide until peptide-peptide binding site saturation was achieved. The size of peptide molecules in solution measured using dynamic light scattering (DLS) (S2 of SI) suggests that a majority of the peptide molecules were in aggregated form in solution therefore peptide-peptide interactions could have already occurred and peptides could have adsorbed to the $\mathrm{ZnO}$ surface as aggregated entities. Therefore, it is possible that initial peptidesurface interaction could have also contributed to the observed endothermic heat effect together with conformational changes between free and bound peptide. Further peptide-peptide interaction could have then occurred characterised by the exothermic heat effect. There was therefore no stepwise process where a monolayer was first completed before multilayer formation; both processes would continue to occur simultaneously once further peptide-peptide interaction on peptide bound to 
$\mathrm{ZnO}$ surface was initiated until saturation was reached. This may explain why stepwise saturation events usually associated with sequential multilayer adsorption was not observed. In support of this explanation, Lindman and coworkers reported multilayer adsorption of human serum albumin (HSA) to copolymer nanoparticles using ITC and similarly did not observe step-wise saturation events in isothermal profiles. ${ }^{25}$

The interaction of G-12A6, G-12A11 and G-12A12 with $\mathrm{ZnO}$ suggests that the respective alanine substitutions in G-12 sequence may have only caused localized changes in peptide structure which did not completely suppress binding potency. This may also suggests that interaction may be mediated by 'hot spot' regions rather than by a single amino acid. Unlike the other three peptides, dilution of G-12A6 into water resulted in a low heat signal which may be attributed to dissociation of peptide molecule aggregates that may have been present at higher peptide concentration in the syringe. This may be linked to the peptide's reported ability to template isotropic growth of $\mathrm{ZnO}$ in solution synthesis forming microspheres. ${ }^{8}$ The concentration of G-12A11 needed to attain saturation was greater than the other three peptides. In G-12A11 (GLHVMHKVAPAR), $P_{11}$ of the original G-12 sequence was replaced with $A_{11}$. The amino acid proline is known to have a restricted backbone conformation because its functional group is cyclised back against the backbone amide position. $.^{8} \mathrm{G}-12 \mathrm{~A} 11$ was the only sequence without a proline-proline dipeptide at position 10 and 11 which may have significantly altered its conformation and packing density at saturation. The determined enthalpy change of the interaction of G-12 and mutants G-12A6, G-12A11 and G-12A12 with $\mathrm{ZnO}$ were similar but G-12 has a slightly greater affinity for the $\mathrm{ZnO}$ surface compared to the mutant sequences.

ITC Study of Interactions of G-12 and GT-16 with ZnO Rods and Platelets. ITC was also used to study the interaction of G-12 and GT-16 with two different morphologies of $\mathrm{ZnO}$ crystals; The 48 -hr $\mathrm{ZnO}$ twinned rods from synthesis using the $\mathrm{Zn}\left(\mathrm{NO}_{3}\right)_{2} \cdot 6 \mathrm{H}_{2} \mathrm{O}$-HMTA system and $\mathrm{ZnO}$ twinned platelets similarly synthesized but also incorporating GT-16 peptide (Figure 2a, b). In comparison to $\mathrm{ZnO}$ rods, $\mathrm{ZnO}$ platelets had a greater surface area of the (ooo1) plane which GT-16 had been reported to preferentially adsorb to. ${ }^{6}$ Previous studies using FTIR reported that the intermediate layered basic zinc nitrate (LBZN) was still present in the $\mathrm{ZnO}$ rods chosen for this study. ${ }^{8}$ Here, using Raman spectroscopy, the symmetric N-O stretching vibration band at $1053 \mathrm{~cm}^{-1}$ for $\mathrm{NO}_{3}^{-}$in LBZN was detected (Figure 2c). The LBZN in $\mathrm{ZnO}$ rods had been quantified using TGA to be $1.6 \pm 0.2 \%$ of the total weight. ${ }^{28}$ This amount was below XPS detection limit as nitrogen ( $\mathrm{N}$ is peak) was not detected the in spectra of the $\mathrm{ZnO}$ rods (Figure $2 \mathrm{~d}$ ). The calculated relation of $\mathrm{Zn} / \mathrm{O}$ was greater than 1 (Table 2) suggesting the presence of oxygen vacancies on the surface. 28,39 The amount of LBZN and peptide adsorbed to $\mathrm{ZnO}$ platelets was quantified (TGA) to be $7.5 \pm 0.5 \%{ }^{28}$ The strong adsorption of GT-16 to washed $\mathrm{ZnO}$ platelets was further confirmed from its Raman spectra by the presence of amide I $\left(\sim 167 \mathrm{o} \mathrm{cm}^{-1}\right)$ band, amide III $\left(\sim 1300 \mathrm{~cm}^{-1}\right)$ band and a peak arising from the amino acid valine $\left(\sim 713 \mathrm{~cm}^{-1}\right)$, all of which were also present in the spectra of GT-16 peptide (Figure 2c). XPS analysis confirmed the presence of GT-16 peptide on the surface of $\mathrm{ZnO}$ platelets by the detection of $\mathrm{N}$ is peak (Figure 2e, Table 2). The higher amount
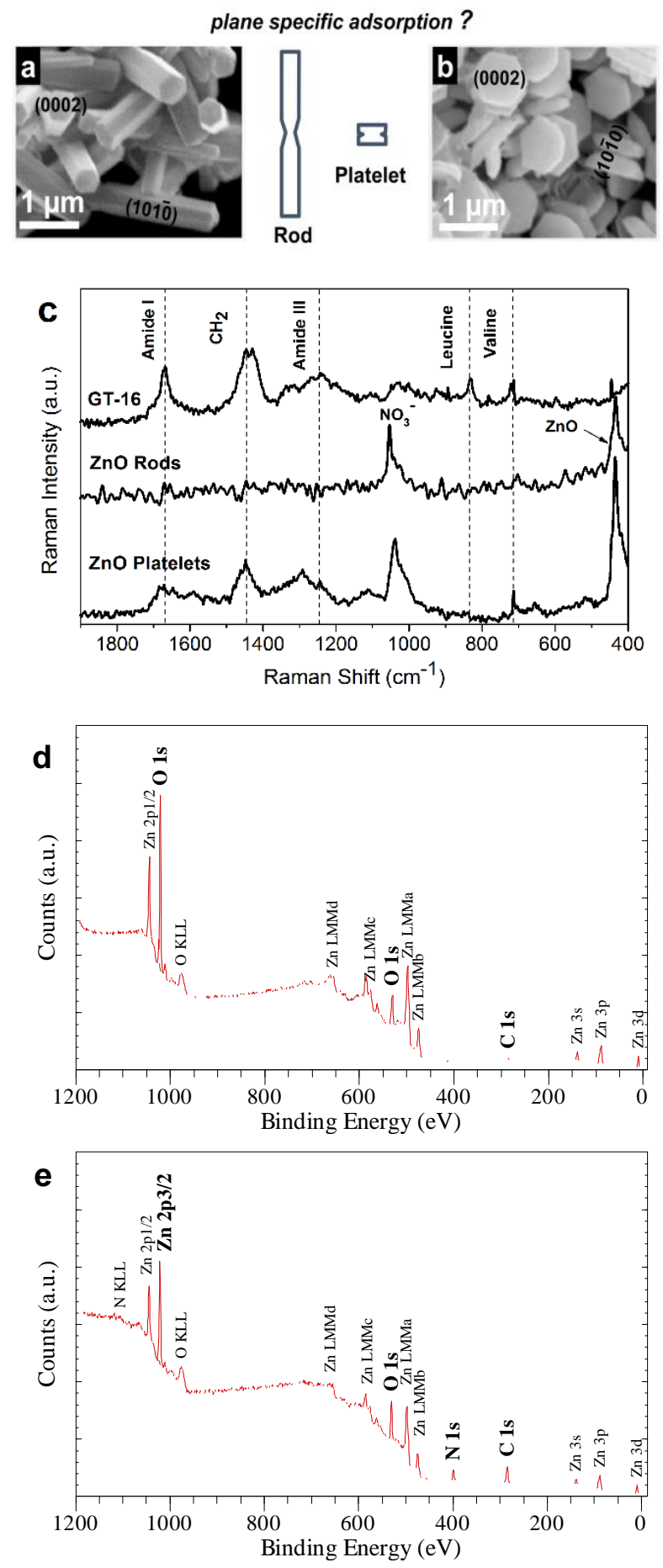

Figure 2. SEM micrographs (a) $\mathrm{ZnO}$ twinned rods, $\mathrm{L} / \mathrm{D}=$ $8.92 \pm 3.26$ and (b) $\mathrm{ZnO}$ twinned platelets $\mathrm{L} / \mathrm{D}=0.69 \pm 0.21$ with schematic representations of the morphologies. (c) Raman spectra of the rods, platelets and GT-16 peptide. (d, e) XPS survey spectrum of the $\mathrm{ZnO}$ rods and platelets respectively.

Table 2. XPS determined Atomic Percentage of $C_{1 s}$, N 1s, $\mathrm{Zn} 2 \mathrm{p3} / 2$ and $\mathrm{O}$ is peaks and the Relative Ratio of $\mathrm{Zn} / \mathrm{O}$

\begin{tabular}{lccccc} 
ZnO Sample & $\% \mathrm{C}$ & $\% \mathrm{~N}$ & $\% \mathrm{Zn}$ & $\% \mathrm{O}$ & $\mathrm{Zn} / \mathrm{O}$ \\
\hline Rods & 7.1 & - & 48.6 & 44.3 & 1.1
\end{tabular}


Platelets

\begin{tabular}{lccccc} 
Rods calcined & 39.1 & 11.1 & 20.8 & 29.0 & \\
\hline & 8.4 & - & 52.3 & 39.3 & 1.3
\end{tabular}

$\mathrm{Zn} / \mathrm{O}$ ratio for platelets not calculated as adsorbed peptide Platelets calcined $43.2 \quad 41.2$ 1.0

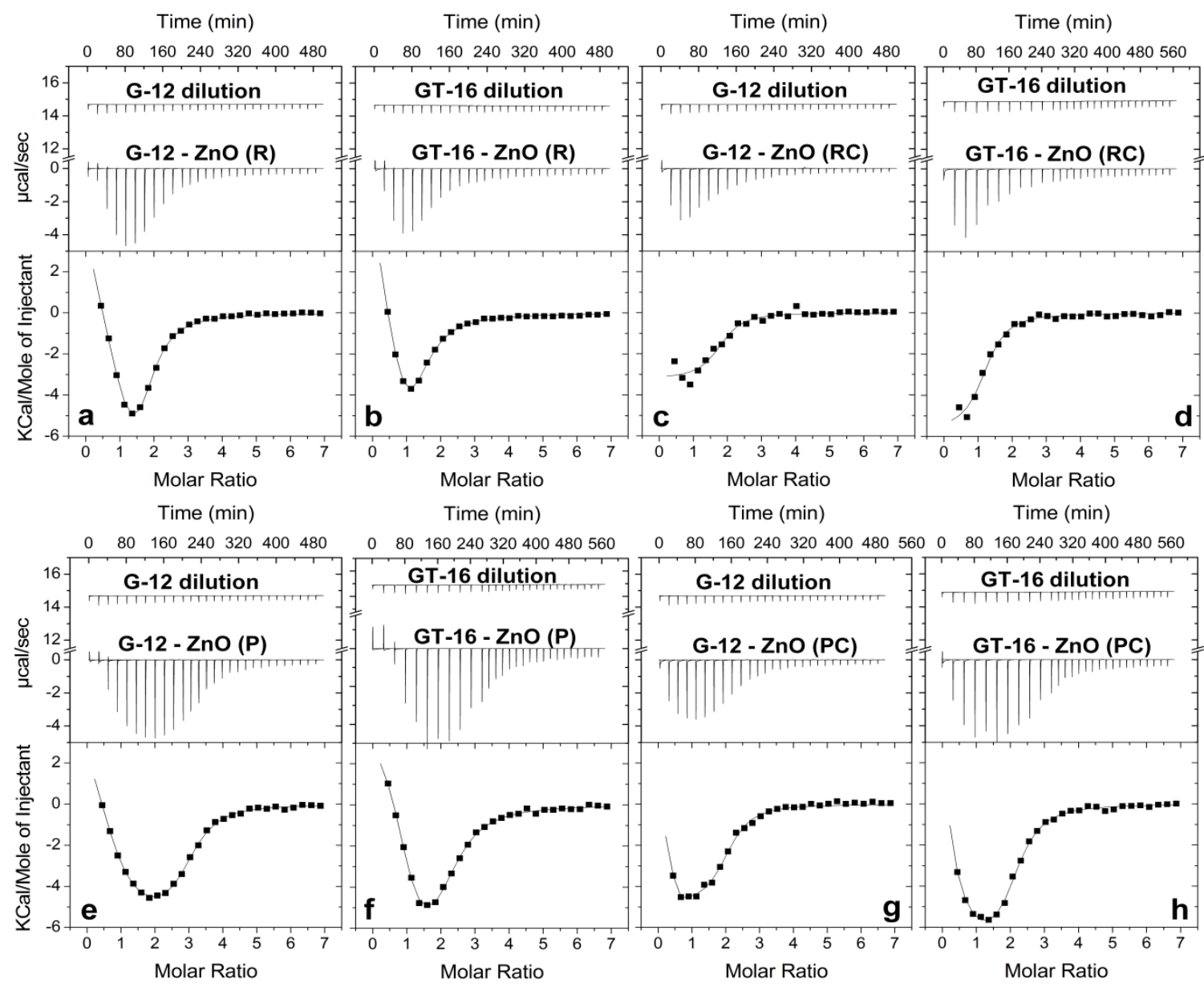

Figure 3. ITC isotherms representing heat effects of interaction measured in the titration of $3.1 \mathrm{mM} \mathrm{G-12} \mathrm{and} \mathrm{GT-16} \mathrm{into} \mathrm{suspen-}$ sions of $\mathrm{ZnO}$ rods (o.1 mM bulk concentration). $\mathrm{ZnO}$ morphologies have been designated; (R) rods, (RC) rods calcined, (P) platelets, (PC) platelets calcined. Titration of peptides into water to measure dilution heats is also shown.

Table 3. Thermodynamic parameters obtained from ITC measurements of interactions between 3.1 mM G-12 and GT-16 and $0.1 \mathrm{mM}$ (bulk concentration) $\mathrm{ZnO}$ twinned rods/platelets. A constant cell temperature of $298 \mathrm{~K}$ was maintained.

Entropy change and Gibbs free energy were calculated using the equation; $\Delta H-T \Delta S=-R T \ln K_{A}=\Delta G$.

\begin{tabular}{|c|c|c|c|c|c|c|}
\hline Peptide and $\mathrm{ZnO}$ & Model & Dp & $K_{A}\left(\mathrm{M}^{-1}\right)$ & $\Delta \mathrm{H}\left(\mathrm{Kcal} \mathrm{mol}^{-1}\right)$ & $\mathrm{T} \Delta \mathrm{S}\left(\mathrm{Kcal} \mathrm{mol}^{-1}\right)$ & $\Delta \mathrm{G}\left(\mathrm{Kcal} \mathrm{mol}^{-1}\right)$ \\
\hline \multirow[t]{2}{*}{ G-12 - ZnO (R) } & 2 & +ve & $1.40 \times 10^{6} \pm 0.33 \times 10^{6}$ & $2.36 \pm 0.68$ & $10.73 \pm 0.55$ & $-8.37 \pm 0.13$ \\
\hline & & -ve & $9.01 \times 10^{4} \pm 0.32 \times 10^{4}$ & $-7.55 \pm 1.09$ & $-0.79 \pm 1.06$ & $-6.76 \pm 0.02$ \\
\hline \multirow[t]{2}{*}{ GT-16 - ZnO (R) } & 2 & +ve & $1.37 \times 10^{5} \pm 2.52 \times 10^{5}$ * & $3.01 \pm 4.16^{*}$ & $10.01^{*}$ & $-7.00 *$ \\
\hline & & -ve & $3.65 \times 10^{4} \pm 3.12 \times 10^{3}$ * & $-3.06 \pm 0.21$ * & $3.16 *$ & $-6.22 *$ \\
\hline G-12 - ZnO (RC) & 1 & -ve & $1.77 \times 10^{5} \pm 0.33 \times 10^{5}$ & $-3.07 \pm 0.21$ & $4.08 \pm 0.34$ & $-7.16 \pm 0.12$ \\
\hline GT-16 - ZnO (RC) & 1 & -ve & $1.31 \times 10^{5} \pm 0.36 \times 10^{5}$ & $-5.54 \pm 0.27$ & $1.44 \pm 0.44$ & $-6.97 \pm 0.17$ \\
\hline \multirow[t]{2}{*}{ G-12 - ZnO (P) } & 2 & +ve & $9.94 \times 10^{5} \pm 2.98 \times 10^{5}$ * & $5.82 \pm 2.4 *$ & $14.01^{*}$ & $-8.19 *$ \\
\hline & & -ve & $1.45 \times 10^{5} \pm 0.21 \times 10^{5}$ & $-6.18 \pm 0.16$ & $0.85 \pm 0.25$ & $-7.04 \pm 0.09$ \\
\hline \multirow[t]{2}{*}{ GT-16 - ZnO (P) } & 2 & +ve & $7.88 \times 10^{5} \pm 2.93 \times 10^{5}$ & $3.48 \pm 1.13$ & $11.49 \pm 0.91$ & $-8.01 \pm 0.22$ \\
\hline & & -ve & $6.32 \times 10^{4} \pm 0.97 \times 10^{4}$ & $-9.42 \pm 0.16$ & $-2.87 \pm 0.24$ & $-6.55 \pm 0.08$ \\
\hline \multirow[t]{2}{*}{ G-12 - ZnO (PC) } & 2 & +ve & - & - & - & - \\
\hline & & -ve & $1.14 \times 10^{5} \pm 0.13 \times 10^{5}$ & $-4.76 \pm 0.36$ & $2.14 \pm 0.28$ & $-6.89 \pm 0.07$ \\
\hline \multirow[t]{2}{*}{ GT-16 - ZnO (PC) } & 2 & +ve & - & - & - & - \\
\hline & & -ve & $1.26 \times 10^{5} \pm 0.04 \times 10^{5}$ & $-8.23 \pm 0.44$ & $-1.27 \pm 0.41$ & $-6.95 \pm 0.02$ \\
\hline
\end{tabular}

R) rods, ( RC) rods calcined, (P) platelets, (PC) platelets calcined, (+ve) endothermic, (-ve) exothermic, (1) one set of sites model, (2) two sets of sites model. Data is an average of at least two measurements, however in some experiments designated 
$(*)$, only one experiment gave reasonable values after fitting, $(-)$ values not calculated as very few data points were obtained in the particular region needed for analysis.

of Carbon ( $\mathrm{C}$ is peak) detected in $\mathrm{ZnO}$ platelets in comparison to that in $\mathrm{ZnO}$ rods could also be attributed to peptide adsorption rather than adventitious carbon (Table 2). There was no evidence of peptide incorporation into the lattice of $\mathrm{ZnO}$ platelets by a comparison of $\mathrm{d}$ spacing values (XRD) for the (10io) plane (for growth along the a-axis) and the (ooor) plane (for growth along caxis) of $\mathrm{ZnO}$ rods against the platelets. ${ }^{8}$ Thus adsorption studies with $\mathrm{ZnO}$ platelets would be characterizing a peptide-peptide adsorption process. ITC experiments were therefore carried out with the particle as directly obtained from solution synthesis and after calcination to $900{ }^{\circ} \mathrm{C}$ to remove adsorbed molecules (chemisorbed water, LBZN and peptide where present). XPS survey spectra of calcined $\mathrm{ZnO}$ rods and platelets in shown in Figure $\mathrm{S}_{3}$ of SI and the atomic percentages of $\mathrm{C}$ 1s, $\mathrm{Zn} 2 \mathrm{p} 3 / 2$ and $\mathrm{O}$ is peaks as well as the relative ratio of $\mathrm{Zn} / \mathrm{O}$ in Table 2 .

Qualitative differences in binding isotherms could be identified when interactions of both peptides ( $G-12$ and GT-16) with the same particles (either rods or platelets, calcined or non-calcined) or the same peptide with different particles was compared (Figure 3). Interestingly, longer time spacing in between injections was needed with GT-16 for the heat effect per injection to return to thermal equilibrium (back to the baseline) compared to G-12. GT16 may have required longer time to attain its stable binding conformation. This was observed with all the particles except the non-calcined $\mathrm{ZnO}$ rods. More injections, hence higher peptide concentration was required to saturate the same mass of $\mathrm{ZnO}$ platelets compared to $\mathrm{ZnO}$ rods which had a lower surface area available for interaction. Calcination of $\mathrm{ZnO}$ caused physico-chemical changes on the surface i.e. removal of chemisorbed water and peptide. These differences are reflected in the changes in the isothermal profiles; the characteristic endothermic and exothermic heat effect of the interaction were still observed but a shift of the isotherm to the right demonstrated that calcination caused changes to the $\mathrm{ZnO}$ surface, affecting interactions at the interface that could be distinguished by the instrument. Depending on the shape of the isotherm, data was fit using either the one or two sets of binding sites model provided by MicroCal (Table 3). Once again, the endothermic process, supported by positive values of $\Delta S$ and $\Delta H$, was attributed to displacement of water, peptide conformational changes and possibly also initial peptidesurface interaction. The exothermic process was attributed to the occurrence of peptide-surface as well as peptidepeptide interactions driven by non-covalent forces. The affinity of G-12 for non-calcined $\mathrm{ZnO}$ rods and platelets appeared to be slightly greater than the affinity of GT-16 however for the calcined crystals the peptides had similar affinity. It was difficult to establish a clear difference in the interaction of GT-16 with the two crystal morphologies that could directly be correlated to the preferential adsorption of GT-16 to (ooo1) plane. Here, the peptides were exposed to interaction with whole crystals as opposed to single crystalline films as in the previous study demonstrating preferential adsorption of GT-16 to (ooo1) plane. ${ }^{6}$ With whole crystals, GT-16 adsorbs to the (ooor) plane but is also able to adsorb to the (1010) plane of $\mathrm{ZnO}$. The likely simultaneous occurrence of peptide-surface and peptide-peptide interactions and the formation of multilayers could have also masked detection of differences in adsorption thermodynamics of the $\mathrm{ZnO}$-BPs examined with the same or different crystal morphologies/surfaces. It has been reported that where peptidepeptide interactions take place forming multilayers, adsorption energies of single peptides can greatly be diminished. ${ }^{40}$ Thus, for this system a direct link between thermodynamic changes and the differences observed in morphology modification in the presence of peptides was difficult to obtain. However, ITC allowed direct characterization of $\mathrm{ZnO}-\mathrm{ZnO}-\mathrm{BP}$ interactions and the quantification of energetic changes occurring during the adsorption process.

It is interesting to note that for the phage display identified peptides, when bound to phages during selection, their ability to form intermolecular interactions and aggregate is restricted. Conversely, artificially synthesized peptides free in solution are able to aggregate through peptide-peptide interactions depending on the amino acid residues present and solution conditions. Nevertheless, these artificially synthesized peptides are still able to interact with the material they were selected against in phage display experiments, though there may be some differences in their interaction. For single chain peptides or aggregated peptides, their interaction with the target surface is dependent on whether they are in a conformation such that the active binding site/important residue (or group of residues), in the 'hot spot' for interaction is available for interaction. Further studies are needed to fully understand the structure of the peptides (single chains, aggregated forms and the effects of the extent of aggregation). More information is needed to define the binding sites on the peptide and the inorganic surface to account for conformational changes including deaggregation of peptide in order to build models that are more representative of the interaction process. In using the one set of identical sites model and two sets of independent sites model, our objective was to fit the data with preferably the fewest adjustable parameters which is synonymous to selecting the simplest binding model that can be used to describe the process..$^{41,42}$ Nevertheless, there are practical difficulties in using these models to fit data for such complex systems as demonstrated in Figure $\mathrm{S}_{4}$ and $\mathrm{S}_{5}$ of SI. More representative and standardized mathematical models can be formulated if additional similar studies are carried out on different material and peptide combinations.

Moreover, as combinatorial methods such as phage display technique have known intrinsic biases associated with their use, development of other complementary approaches for identification and selection of specific material binding peptides are to be encouraged. ${ }^{43-45}$ Molecular simulation techniques allow for theoretical investigation of the behaviour of complex systems at a molecular level 
beyond what can presently be achieved experimentally.46,47 Information obtained from ITC studies can be used to improve computational simulation strategies and validate the design of force fields to more accurately describe peptide-peptide and peptide-inorganic interactions. Furthermore, we propose the use of ITC as a screening method to distinguish between strong and weak binders by determining peptide affinity for target substrates. This may be particularly clear where adsorption processes are saturated within or close to monolayer coverage. Much progress is needed to accelerate the rationale used to identify inorganic binding peptides with integrated properties and functionality.

\section{CONCLUSIONS}

Using ITC, the interaction of $\mathrm{ZnO}$ and $\mathrm{ZnO}$-BPs has been shown to occur through a biphasic process involving and endothermic and exothermic event. High adsorption affinity values indicated the occurrence of favourable interactions with $\Delta G$ values between -6 and $-8.5 \mathrm{kcal} / \mathrm{mol}$. The adsorption of the $\mathrm{ZnO}$-BPs was seen to be a process involving simultaneous interactions i.e. peptide-solvent, substrate-solvent, peptide-surface, possible conformation changes between bound and free peptide states and peptide-peptide interactions. The wider use of ITC to study other peptide-inorganic interaction systems, in combination with other conventional techniques used to kinetically/thermodynamically characterize peptide-inorganic interactions may collectively build knowledge that can enable control over material formation processes to be achieved, mastered and exploited to advance material design processes. Though the use of ITC to monitor biotic-abiotic interactions has its challenges, with continued improvements in instrumentation, methodology and binding models, its development for novel applications is far from being exhausted.

\section{ASSOCIATED CONTENT}

Supporting Information. Text $S_{1}$, Figure $S_{2}$ to $S_{5}$. This material is available free of charge via the Internet at http://pubs.acs.org.

\section{AUTHOR INFORMATION}

\section{Corresponding Author}

*Email: Carole.Perry@ntu.ac.uk

\section{Author Contributions}

All authors have given approval to the final version of the manuscript.

\section{Funding Sources}

U.S. Air Force Office of Scientific Research (AFOSR) for funding (FA9550-10-1-0024) and (FA9550-13-1-0040).

\section{Notes}

The authors declare no competing financial interest.

\section{ACKNOWLEDGMENT}

We would like to thank Dr. Graham J. Hickman for performing mass spectrometry analysis of the peptides studied, Dr. David J. Belton for the surface area measurements of $\mathrm{ZnO}$ particles, Anna Sola-Rabada and Mr. Martin J. Roe (Advanced Materials Research Group, X-ray Photoelectron Spectroscopy, Faculty of Engineering, The University of Notting- ham) for the X-ray photoelectron spectroscopy analysis of $\mathrm{ZnO}$ particles. We are grateful to the U.S. Air Force Office of Scientific Research (AFOSR) for funding this fundamental research study.

\section{REFERENCES}

(1) Tomczak, M. M.; Gupta, M. K.; Drummy, L. F.; Rozenzhak, S. M.; Naik, R. R. Morphological Control and Assembly of Zinc Oxide Using a Biotemplate. Acta Biomater. 2009, 5, 876-882.

(2) Chiu, C. Y.; Li, Y.; Ruan, L.; Ye, X.; Murray, C. B.; Huang, Y. Platinum Nanocrystals Selectively Shaped Using Facet-specific Peptide Sequences. Nature Chemistry 2011, 3, 393-399.

(3) Chiu, C.; Ruan, L.; Huang, Y. Biomolecular Specificity Controlled Nanomaterial Synthesis. Chem. Soc. Rev. 2013, 42, 25122527.

(4) Ruan, L.; Ramezani-Dakhel, H.; Chiu, C.; Zhu, E.; Li, Y.; Heinz, H.; Huang, Y. Tailoring Molecular Specificity Toward a Crystal Facet: a Lesson From Biorecognition Toward Pt $\{111\}$. Nano Lett. 2013, 13, 840-846.

(5) Togashi, T.; Yokoo, N.; Umetsu, M.; Ohara, S.; Naka, T.; Takami, S.; Abe, H.; Kumagai, I.; Adschiri, T. Material-binding Peptide Application - ZnO Crystal Structure Control by Means of a ZnO-binding Peptide. J. Biosci. Bioeng. 2011, 111, 140-145.

(6) Liang, M.; Deschaume, O.; Patwardhan, S. V.; Perry, C. C. Direct Evidence of $\mathrm{ZnO}$ Morphology Modification via the Selective Adsorption of $\mathrm{ZnO}$-binding Peptides. J. Mater. Chem. 2o11, 21, 80-89.

(7) Baier, J.; Naumburg, T.; Blumenstein, N. J.; Jeurgens, L. P.; Welzel, U.; Do, T. A.; Pleiss, J.; Bill, J. Bio-inspired Mineralization of Zinc Oxide in Presence of ZnO-binding Peptides. Biointerface Res. Appl. Chem. 2012, 2, 380-391.

(8) Limo, M. J.; Ramasamy, R.; Perry, C. C. ZnO Binding Peptides: Smart Versatile Tools for Controlled Modification of $\mathrm{ZnO}$ Growth Mechanism and Morphology. Chem. Mater. 2015, 27, 1950-1960.

(9)Brown, S.; Sarikaya, M.; Johnson, E. A Genetic Analysis of Crystal Growth. J. Mol. Biol. 20oo, 299, 725-735.

(10) Slocik, J. M.; Stone, M. O.; Naik, R. R. Synthesis of Gold Nanoparticles Using Multifunctional Peptides. Small 2005, 1, 10481052.

(11) Kim, J.; Rheem, Y.; Yoo, B.; Chong, Y.; Bozhilov, K. N.; Kim, D.; Sadowsky, M. J.; Hur, H.; Myung, N. V. Peptide-mediated Shape-and Size-tunable Synthesis of Gold Nanostructures. Acta Biomater. 2010, 6, 2681-2689.

(12) Chiu, C.; Li, Y.; Huang, Y. Size-controlled Synthesis of Pd Nanocrystals Using a Specific Multifunctional Peptide. Nanoscale 2010, 2, 927-930.

(13) Xie, J.; Lee, J. Y.; Wang, D. I.; Ting, Y. P. Silver Nanoplates: from Biological to Biomimetic Synthesis. ACS Nano 2007, 1, 429439.

(14) Patwardhan, S. V.; Patwardhan, G.; Perry, C. C. Interactions of Biomolecules with Inorganic Materials: Principles, Applications and Future Prospects. J. of Mater. Chem. 2007, 17, 28752884 .

(15) Whyburn, G. P.; Li, Y. J.; Huang, Y. Protein and Protein Assembly Based Material Structures. J. of Mater. Chem. 2008, 18, 3755-3762.

(16) Cedervall, T.; Lynch, I.; Lindman, S.; Berggård, T.; Thulin, E.; Nilsson, H.; Dawson, K. A.; Linse, S. Understanding the Nanoparticle-Protein Corona Using Methods to Quantify Exchange Rates and Affinities of Proteins for Nanoparticles. Proc. Natl. Acad. Sci. 2007, 104, 2050-2055.

(17) Perry, C. C.; Patwardhan, S. V.; Deschaume, O. From Biominerals to Biomaterials: the Role of Biomolecule-Mineral Interactions. Biochem. Soc. Trans. 2009, 37, 687-691. 
(18) Sola-Rabada, A.; Liang, M.; Roe, M. J.; Perry, C. C. Peptidedirected crystal growth modification in the formation of $\mathrm{ZnO}$. J. Mater. Chem. B 2015, 3, 3777-3788.

(19) Masuda, Y.; Kinoshita, N.; Koumoto, K. Morphology Control of ZnO Crystalline Particles in Aqueous Solution. Electrochim. Acta 2007, 53, 171-174.

(20) Yokoo, N.; Togashi, T.; Umetsu, M.; Tsumoto, K.; Hattori, T.; Nakanishi, T.; Ohara, S.; Takami, S.; Naka, T.; Abe, H.; Kumagai, I.; Adschiri, T. Direct and Selective Immobilization of Proteins by Means of an Inorganic Material-Binding Peptide: Discussion on Functionalization in the Elongation to MaterialBinding Peptide. J. Phys. Chem. B 2010, 114, 480-486.

(21) Okochi, M.; Sugita, T.; Furusawa, S.; Umetsu, M.; Adschiri, T.; Honda, H. Peptide Array-based Characterization and Design of ZnO-high Affinity Peptides. Biotechnol. Bioeng. 2010, 106, $845-851$.

(22) Rothenstein, D.; Claasen, B.; Omiecienski, B.; Lammel, P.; Bill, J. Isolation of ZnO-binding 12-mer Peptides and Determination of their Binding Epitopes by NMR Spectroscopy. J. Am. Chem. Soc. 2012, 134, 12547-12556.

(23) Lynch, I.; Dawson, K. A. Protein-Nanoparticle Interactions. Nano Today 2008, 3, 40-47.

(24) Huang, R.; Carney, R.; Stellacci, F.; Lau, B. ProteinNanoparticle Interactions: The Effects of Surface Compositional and Structural Heterogeneity is Scale Dependent. Nanoscale 2013, 5, 6928-6935.

(25) Lindman, S.; Lynch, I.; Thulin, E.; Nilsson, H.; Dawson, K. A.; Linse, S. Systematic Investigation of the Thermodynamics of HSA Adsorption to $\mathrm{N}$-iso-propylacrylamide/N-tertbutylacrylamide Copolymer Nanoparticles. Effects of Particle Size and Hydrophobicity. Nano Lett. 2007, 7, 914-920.

(26) Ababou, A.; Ladbury, J. E. Survey of the Year 2004: Literature on Applications of Isothermal Titration Calorimetry. J. Mol. Recognit. 2006, 19, 79-89.

(27) Cliff, M. J.; Gutierrez, A.; Ladbury, J. E. A Survey of the Year 2003 Literature on Applications of Isothermal Titration Calorimetry. J. Mol. Recognit. 2004, 17, 513-523.

(28) Liang, M.; Limo, M. J.; Rabada, A. S.; Roe, M.; Perry, C. C. New Insights into the Mechanism of $\mathrm{ZnO}$ Formation from Aqueous Solutions of Zinc Acetate and Zinc Nitrate. Chem. Mater. 2014, 26, 4119-4129.

(29) MicroCal, L. ITC Data Analysis in Origin Tutorial Guide; Northampton, MA, USA, 2004.

(30) Cohavi, O.; Reichmann, D.; Abramovich, R.; Tesler, A. B.; Bellapadrona, G.; Kokh, D. B.; Wade, R. C.; Vaskevich, A.; Rubinstein, I.; Schreiber, G. A Quantitative, Real-Time Assessment of Binding of Peptides and Proteins to Gold Surfaces. Chem. Eur. J. 2011, 17, 1327-1336.

(31) Goobes, G.; Goobes, R.; Shaw, W. J.; Gibson, J. M.; Long, J. R.; Raghunathan, V.; Schueler-Furman, O.; Popham, J. M.; Baker, D.; Campbell, C. T. The Structure, Dynamics, and Energetics of Protein Adsorption - Lessons Learned from Adsorption of Statherin to Hydroxyapatite. Magn. Reson. Chem. 2007, 45, S32-S47. (32) Goobes, R.; Goobes, G.; Shaw, W. J.; Drobny, G. P.; Campbell, C. T.; Stayton, P. S. Thermodynamic Roles of Basic Amino Acids in Statherin Recognition of Hydroxyapatite. Biochemistry 2007, 46, 4725-4733.

(33) Myszka, D.; Abdiche, Y.; Arisaka, F.; Byron, O.; Eisenstein, E.; Hensley, P.; Thomson, J.; Lombardo, C.; Schwarz, F.; Stafford, W.; Doyle, M. L. The ABRF-MIRG'or Study: Assembly State, Thermodynamic, and Kinetic Analysis of an Enzyme/Inhibitor Interaction. J. Biomol. Tech. 2003, 14, 247.

(34) Chiad, K.; Stelzig, S. H.; Gropeanu, R.; Weil, T.; Klapper, M.; Mullen, K. Isothermal Titration Calorimetry: A Powerful Technique to Quantify Interactions in Polymer Hybrid Systems. Macromol. 2009, 42, 7545-7552.

(35) Bouchemal, K.; Mazzaferro, S. How to Conduct and Interpret ITC Experiments Accurately for Cyclodextrin-Guest Interactions. Drug Discov. Today 2012, 17, 623-629.
(36) Degen, A.; Kosec, M. Effect of $\mathrm{pH}$ and Impurities on the Surface Charge of Zinc Oxide in Aqueous Solution. J. Eur. Ceram. Soc. 200o, 20, 667-673.

(37) Leavitt, S.; Freire, E. Direct Measurement of Protein Binding Energetics by Isothermal Titration Calorimetry. Curr. Opin. Struct. Biol. 2001, 11, 560-566.

(38) Williamson, M. P. The Structure and Function of Prolinerich Regions in Proteins. Biochem. J. 1994, 297, 249-260.

(39) Zheng, Y.; Chen, C.; Zhan, Y.; Lin, X.; Zheng, Q.; Wei, K.; Zhu, J.; Zhu, Y. Luminescence and Photocatalytic Activity of ZnO Nanocrystals: Correlation between Structure and Property. Inorg. Chem. 20o7, 46, 6675-6682.

(40) Coppage, R.; Slocik, J. M.; Briggs, B. D.; Frenkel, A. I.; Naik, R. R.; Knecht, M. R. Determining Peptide Sequence Effects That Control the Size, Structure, and Function of Nanoparticles. ACS Nano 2012, 6, 1625-1636.

(41) Schmidtchen, F. P. Isothermal Titration Calorimetry in Supramolecular Chemistry. In Analytical methods in supramolecular chemistry; Wiley VCH, 2012, 67-103.

(42) Limo, M. J.; Perry, C. C.; Thyparambil, A.; Wei, Y.; Latour, R. A. In Experimental Characterization of Peptide-Surface Interactions; Bio-Inspired Nanotechnology; Springer, 2014, 37-94.

(43) Puddu, V.; Perry, C. C. Peptide Adsorption on Silica Nanoparticles: Evidence of Hydrophobic Interactions. ACS Nano 2012, 6, 6356-6363.

(44) Vodnik, M.; Zager, U.; Strukelj, B.; Lunder, M. Phage Display: Selecting Straws Instead of a Needle from a Haystack. Molecules 2011, 16, 790-817.

(45) Slocik, J. M.; Naik, R. R. Probing Peptide-Nanomaterial Interactions. Chem. Soc. Rev. 2010, 39, 3454-3463.

(46) Di Felice, R.; Corni, S. Simulation of Peptide-Surface Recognition. J. Phys. Chem. Lett. 2011, 2, 1510-1519.

(47) Pandey, R. B.; Heinz, H.; Feng, J.; Farmer, B. L.; Slocik, J. M.; Drummy, L. F.; Naik, R. R. Adsorption of Peptides (A3, Flg, $\mathrm{Pd}_{2}, \mathrm{Pd}_{4}$ ) on Gold and Palladium Surfaces by a Coarse-grained Monte Carlo Simulation. Phys. Chem. Chem. Phys. 20o9, 11, 19892001. 


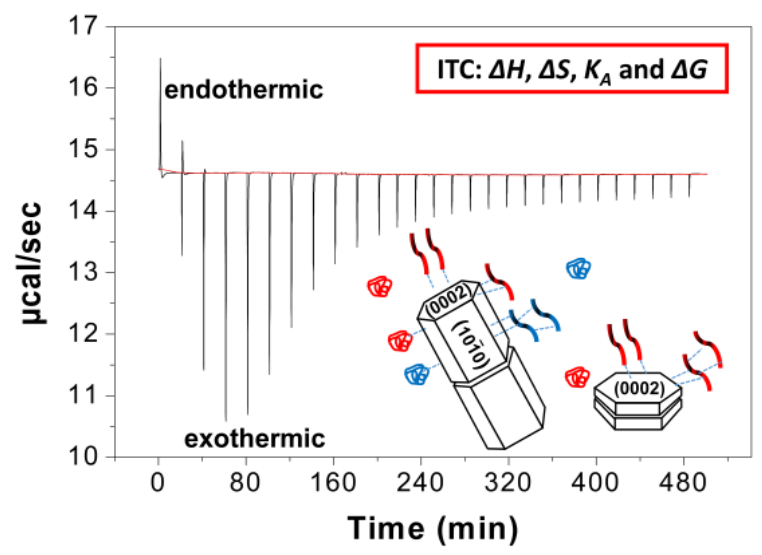

